\title{
AS MODAS E O CELIBATO: EDUCAÇÃO E NORMALIZAÇÃO SOCIAL NO RIO GRANDE DO NORTE NA DÉCADA DE 1920
}

\author{
Antonio Basilio Novaes Thomaz de Menezes \\ Universidade Federal do Rio Grande do Norte - UFRN
}

\begin{abstract}
RESUMO
Este artigo trata da normalização social na década de 1920, a partir do recorte histórico da produção do discurso educacional no Rio Grande do Norte, tomando por referencia o quadro conceitual de Michel Foucault, especificamente os conceitos de discurso, normalização e dispositivo. Examina a concepção de "educação completa" do professor potiguar Nestor dos Santos Lima, fazendo uma análise de duas publicações: As Modas e a Educação, um artigo publicado na revista Pedagogium em 1921 e O Celibato Pedagógico, libreto da tese apresentada no I Congresso Nacional de Educação em1927. E por fim tal análise procura estabelecer um paralelo entre estas publicações, mostrando como o conteúdo das diferentes temáticas caracteriza um dispositivo de normalização social, a partir da presença dos pressupostos higienistas na concepção educacional do autor, especificamente no que diz respeito à formação e ao exercício profissional.

Palavras-chave: história; educação; higiene; dispositivo; normalização.
\end{abstract}

\section{FASHIONS AND CELIBATE: EDUCATION AND SOCIAL NORMALIZATION IN 1920'S, RIO GRANDE DO NORTE}

\section{ABSTRACT}

This paper aims to analyze social normalization in the 1920's from the point of view of the production of educational discourse in Rio Grande do Norte, having as theoretical background the concepts of Michel Foucault (discourse, normalization, dispositif). We intend to look carefully at the concept of «complete education» from potiguar professor Nestor dos Santos Lima, focusing on two of his works: «As Modas e a Educação», a paper published on Pedagogium in 1921, and «O Celibato Pedagógico», script of the thesis introduced in the first national meeting on education in 1927. We aim to establish a parallel between those publications, showing how is characterized a kind of dispositif of social normalization, informing the hygienists assumptions on education of Nestor dos Santos Lima, mainly concerning professional training and exercise.

Keywords: history; education; hygiene; dispositif; normalization.

\section{CONSIDERAÇÕES INICIAIS:}

Ainda que pareçam estranhas ao campo da educação, as temáticas da moda e do celibato emergem no quadro histórico do Rio Grande do Norte, a luz de um recorte do discurso educacional da década de 1920 que atravessa as concepções dos educadores e expõe o higienismo como um dispositivo de normalização social próprio do início do século XX. Com temáticas específicas, referenciadas por diferentes momentos e situações diversas, os respectivos conteúdos, objeto de análise deste estudo, transpõem sua condição particular para o plano geral dos enunciados, a partir do pressuposto higienista da concepção educacional do professor Nestor dos Santos Lima que aponta para o quadro mais amplo das condições de formulação do discurso educacional em determinada época. As publicações As Modas e A 
Educação de 1921 e O Celibato Pedagógico de 1927, obras do referido autor, compreendem no núcleo estruturador da sua perspectiva educacional a vigência de todo um discurso, entendido como um conjunto de enunciados de diferentes campos que obedecem à uma regra comum de funcionamento, e operam mecanismos de organização do real por meio da produção de saberes, estratégias e práticas (FOUCAULT, 1969).

Configurado na matriz do discurso educacional da época, o higienismo constitui um pressuposto central na noção de "educação completa" de Nestor Lima (RIO GRANDE DO NORTE, 1912, p.18), enunciada uma década antes e orientadora da abordagem das temáticas da moda e do celibato. O pressuposto higienista corroborado pela compreensão de uma educação completa caracteriza-se a partir de um conjunto de enunciados e práticas médicas circulantes, relacionadas à educação e materializadas em diferentes instituições. Como tal ele consubstancia um dispositivo da perspectiva educacional enquanto um operador material do poder na ordem do discurso. Isto é, materializa na abordagem dos temas do celibato e das modas um "dispositivo de saber" ou um conjunto heterogêneo de instituições, organizações arquitetônicas, medidas administrativas e enunciados científicos entre outros, englobando técnicas, estratégias e formas de assujeitamento social (FOUCAULT, 1976).

Nesses termos, o higienismo pressuposto a compreensão de uma educação completa expressa a materialidade do quadro histórico da medicalização da sociedade na década de 1920, evidenciando, enquanto dispositivo de saber, o plano prático de um discurso educacional biologizante, estruturado em torno da distinção normal e anormal. Esta mesma que por si apresenta uma função normalizadora ao introduzir a prevenção como fator das medidas de correção e atribuir aos meios de correção toda uma tecnologia de comportamento humano e transformação do indivíduo (FOUCAULT, 1984). De tal modo que, a interrelação das temáticas articula nos seus respectivos eixos o horizonte comum da normalização, da função social de um dispositivo de saber que, constituído na forma de um "dispositivo clínico" (FOUCAULT, 1984), expõe o seu significado educacional através da ótica dos processos e procedimentos inscritos no âmbito da regulação da ordem e do corpo social (FOUCAULT, 1975).

Em síntese, este artigo se propõe examinar os pressupostos higienistas dos quais emergem os pontos de discussão: sobre a condição fisiológica feminina e as exigências do exercício do magistério na tese O Celibato Pedagógico (LIMA, 1927); e sobre a necessidade moral, patriótica e climática da adoção de uniformes pelos alunos da Escola Normal no artigo As Modas e A Educação (LIMA, 1921a), ambos postos à luz da perspectiva educacional de Nestor Lima. Contemplando assim um percurso de análise que se inicia com uma abordagem sinótica reunindo autor, pressupostos e quadro de época; passa para análise da relação entre o discurso educacional e a noção de "educação completa" (RIO GRANDE DO NORTE, 1912, p.18); e chega finalmente ao objeto de investigação associado às temáticas.

\section{O AUTOR, OS PRESSUPOSTOS E O QUADRO DE ÉPOCA}

Personagem central na história da educação no Rio Grande do Norte, agente da implementação de políticas educacionais no contexto das reformas educacionais de 1908 e 1916, e da reforma administrativa de 1924, no período da República Velha, Nestor Lima foi professor de Pedagogia e de Pedologia, depois Diretor da Escola Normal de Natal entre 1910 e 1923; ocupou a direção da Instrução Pública e foi o primeiro diretor do recém criado Departamento de Educação do Estado no período de 1924 a 1928, tendo ainda lecionado Psicologia Infantil entre 1928 e 1934 na Escola Normal, encerrando sua trajetória no ensino como professor e diretor da Faculdade de Direito. 
Pioneira, a produção intelectual de Nestor Lima compreende um amplo espectro que cobre os aspectos do modelo escolar, da metodologia didático-pedagógica, da disciplina escolar e da política de ensino institucional. Seus elementos constituem um discurso educacional que se estabelece através dos documentos, situados no campo epistêmico dos enunciados e no contexto das práticas sócio-pedagógicas vigentes, os quais, juntos, delineiam uma compreensão educacional que se articula em termos do Rio Grande do Norte, considerado dentro do quadro histórico das suas condições específicas.

Assim a importância da figura histórica de Nestor Lima subsume sua relevância a construção pedagógico-educacional da concepção de "educação completa", na qual articula diferentes camadas do enunciado na relação entre prática e discurso, estabelecida no campo do ordenamento epistêmico e das categorias historicamente constituídas.

A relação do Higienismo com a Educação, que marca o discurso educacional na década de 1920, situa-se no campo da épistèmé ou da forma de organização dos saberes configurada a partir do século XIX, das Ciências Humanas fundadas no universal Homem, em torno do qual se estabelece um novo quadro de saberes como forma de delimitar a multiplicidade dos indivíduos aos aspectos modelares: trabalho, vida biológica e linguagem (FOUCAULT, 1966). A Ciência da Educação dentre estes saberes emerge como parte desse quadro histórico demarcando a sua condição limítrofe em relação às novas formas de saber que lhe constituem o objeto da prática pedagógica. Por exemplo, aquilo que cabe no campo teórico a uma Pedagogia Científica (PIZZOLI,1910), a Psicologia da Educação (LE BON, 1909) ou ainda a Psicologia da Criança e Pedagogia Experimental (CLAPARÈDE, 1911) consubstancia-se em marcos referenciais de uma compreensão capaz de elaborar um conhecimento específico sobre o objeto educacional nas ordens biológica, cognitiva e moral.

O higienismo se associa a este novo quadro de saberes como uma ideologia científica (CANGUILHEM, 1983) ou algo próprio a produção e a prática científica, que não se caracteriza como Ciência no sentido rigoroso dos protocolos. Cabe ao Higienismo uma fundamentação prática, com caráter científico advindo dos saberes médicos, que superpõe ao pressuposto das condições biológicas de saúde física e mental a proposta da Ciência da Educação de uma boa formação física, intelectual e moral do indivíduo. De tal modo que as relações entre educação e higienismo se delineiam no espaço que descreve uma forma de organização dos saberes da época cujas formações discursivas se articulam em torno de um eixo tripartido - fisiológico, psíquico e moral - do indivíduo tomado sob a ótica universal do Homem.

Os pressupostos higienistas no discurso educacional da década de 1920 circunscrevem, no Brasil, um recorte histórico que contempla o final do século XIX, o advento da República e as três primeiras décadas do século XX, de consolidação da nova ordem. Período caracterizado por todo um quadro de conformação da sociedade brasileira concomitante as mudanças operadas no status quo. Nele, o ideário republicano de ordem e progresso se associa ao de uma modernização emergente, das descobertas científicas, das inovações técnicas e das máquinas, da urbanização e industrialização progressivas, em paralelo ao esforço de construção das novas instituições e a tentativa de criação de uma identidade nacional para o país estabelecida em torno de um modelo social. Sanear as cidades, modelar os costumes, disciplinar as populações, higienizar a sociedade de todos os males que obstam o progresso são então perspectivas de intervenção social desse período que se coloca no contexto histórico de uma efervescência cultural articulada sobre os eixos do saber médico e pedagógico, enfatizado no papel social da educação em torno da proposta de uma formação completa - física, intelectual e moral - do brasileiro capaz de delinear uma identidade nacional para o Brasil republicano. 
Situando-se dentro deste quadro histórico com suas particularidades específicas o discurso educacional no Rio Grande do Norte se configura em meio a um processo de modernização da sociedade dentro de uma estrutura conservadora. Alvo de constante de epidemias desde o século XIX; "a primeira epidemia que alarmou o Rio Grande do Norte foi, em 1850, a febre amarela" (CASCUDO, 2002, p.29); as ações de modernização empreendidas no decorrer das primeiras décadas do século XX limitaram-se ao remodelamento urbanístico da capital - iluminação elétrica, bondes, bairros novos - e as obras de infra-estrutura voltadas para produção - reforma do porto, rodagem, ferrovias, açudes e prédios públicos - só empreendendo na década de 1920 uma política de intervenção social com a criação dos serviços de Profilaxia das Doenças Venéreas e Profilaxia e Saneamento Rural (CASCUDO, 1955, p.220).

É no campo educacional, contudo, que uma política de intervenção social faz-se visível com as reformas do ensino de 1908 e 1916 (RIO GRANDE DO NORTE, 1913, 1917), voltadas para a formação primária da população potiguar. A criação da Escola Normal de Natal, do Grupo Escolar - Escola Modelo Augusto Severo - em 1908 e a proliferação de Grupos Escolares pelo interior do Estado na década de 1920, associam-se uma reorganização administrativa do ensino - Grupos Escolares, Escolas Reunidas, Escolas Isoladas e Escolas Rudimentares - e a criação, em 1924, do Departamento e do Conselho de Educação do Estado (RIO GRANDE DO NORTE, 1930), como iniciativas de normalização institucional no âmbito da formação social. De tal modo que, o discurso educacional de Nestor Lima delineiase a partir de um espaço de relações que define neste contexto os seus pressupostos em torno de um modelo social próprio inscrito na cultura da sociedade.

A influência do pensamento higienista na concepção educacional da época se faz notar na divulgação das idéias científicas pelos jornais literários existentes em Natal, movimento que tem no professor Cristovam Dantas - titular da cadeira de Higiene no colégio Atheneu norte-rio-grandense - um dos seus maiores entusiastas. Dantas inaugura as reflexões acerca da eugenia num artigo publicado pela Revista do Centro Polimático do Rio Grande do Norte com o título "A criança e a eugenia" em 1920. Sua concepção de uma eugenia mitigada superpõe a noção higienista de regeneração à perspectiva de reconstrução da cultura ou de "reconstruir o homem, o pensamento, a moral, os costumes: a escola, o lar; reconstruir o caráter" (DANTAS, 1920, p.3). Nessa medida, a educação infantil se coloca sob as leis da higiene como condição da regeneração da raça, tanto em termos de produção do indivíduo saudável, quanto em termos da profilaxia social dos indivíduos nocivos, obedecendo a critérios prévios como o autor assinala na sua "Tabela de Robustez" (DANTAS, 1920, p.7).

De outro modo, a influência do quadro referencial higienista se apresenta disperso no discurso pedagógico de Nestor Lima, a exemplo de um artigo publicado em 1911, na coluna Pedagogia do jornal a República. Nele, o autor ao tratar de métodos e processos no ensino de Moral e Cívica e Economia Doméstica, assevera que "um mestre deve lançar mão para influir sobre a conduta de seus discípulos no tocante ao desprezo do vício e ao culto do bem, da virtude, da energia e da coragem", ressaltando o papel da família no ensino doméstico uma vez que "nos cuidados necessários à direção da casa, dos filhos e à economia e higiene da família e da habitação nos tratamentos das moléstias etc." (LIMA, 1911, p. 2) se encontra a base de toda existência social.

A presença dos pressupostos higienistas na concepção educacional de Nestor Lima se configura na história da sua própria construção "sob o aspecto específico da análise do quadro de possibilidades da formação do discurso e sua dimensão histórica” (MENEZES, 2003, p.10). Materializados nos volumes da sua biblioteca particular encontram-se os pressupostos da construção de todo um discurso, alicerçado no jogo da organização dos saberes da época, o qual serve de modelo para a produção intelectual norte-rio-grandense. Os saberes guardados 
na biblioteca tornam efetiva a transparência da èpistèmé como todo um conjunto de vozes de autores que, aparentemente dissonantes, revelam-se uníssonos e ecoam na construção discursiva do autor.

Psicologia, Medicina e Pedologia são alguns dos saberes que se encontram disseminados nas publicações de Nestor Lima, reunidos numa rede de múltiplos entrelaçamentos, os quais descrevem o campo pedagógico-educacional dos pressupostos higienistas. Estes se fazem presentes na produção intelectual do autor nas suas referências as obras de Compayré (1906, 1908), Dufestel (1909), Le Bon (1909), Paulhan (1909), Pizzoli (1910), Claparède (1911), Quaglio (1911), Lassablière (1911), Montessori (1915) e Afrânio Peixoto (1914) que, entre outras, constituem uma matriz de pensamento expressa nas suas concepções. Assim, a concepção pedagógico-educacional de Nestor Lima não se furta a presença dos pressupostos centrais do pensamento higienista expresso, por exemplo pela categoria "anormal" como eixo de articulação dos seus enunciados.

A categoria "anormal", pertinente a todo tipo de problematização e expressa na amplitude das formulações higienistas, constitui-se na condição necessária de uma normalização higiênica que se efetiva tanto nos parâmetros culturais como nos padrões de comportamento individuais relativos ao conjunto da sociedade. Exemplo claro encontra-se na concepção educacional que baliza as observações de Nestor Lima no relatório que publicou sobre o ensino no Sul do Brasil e no Rio da Prata (LIMA, 1923), especificamente na descrição das "escolas especiais" de Montevidéu, particularmente em torno da "classe dos anormais":

Estas são as crianças das escolas comuns, que, por exame médico, demonstraram irregularidade mental, como instáveis ou apáticas que são na realidade. Eu visitei a todas. Aqui uma criança de oito anos, mirradinha, de rosto coberto de sardas e espinhas, tem os movimentos incertos e arrítmicos de um desequilibrado: ali, outra tem os movimentos lentos e demorados, de um imbecil; aqui, outra é um tipo de bobo, aos catorze anos, já púbere, ri de tudo e tem a fisionomia típica dos anormais (...) surge um pretinho - Baêza refugo das escolas comuns, onde era a causa de desordem permanente e a quem tudo de mal se atribuía invariavelmente. Este tem um ano de classe e já tem melhorado sensivelmente (...) O trabalho é penosíssimo de uma paciência ultraevangélica; pois dar ocupação manual e ensinar por meios ativos aquela classe de irregulares profundos e dela conseguir algum adiantamento é sinal de grande merecimento. (LIMA, 1923, p.27).

De outro modo, é também sob uma perspectiva intervencionista de desenvolvimento das políticas de ensino que aparece na concepção educacional de Nestor Lima uma expressão da presença do pensamento higienista, tal como encontramos na sua síntese histórica do movimento pedagógico no Rio Grande do Norte:

Ainda há poucos anos, em plena vigência da nossa Reforma, houve ensejo de horrorizarem-se-me os olhos afeitos a métodos sistemáticos de instrução. Foi na risonha povoação de Campestre, distante cerca de oito léguas de Nova Cruz, que eu presenciei a classe de um mestre-escola de antanho, tipo completo da rotina e da ignorância profissional, que entre nós já reinaram. Imaginemos um mulatagão de quase dois metros de altura, tez carregada reumático, puxando a uns 70 janeiros, vasto, nariz rombóide cavalgado pelos ocultos sem grau, tendo à roda de si seis ou oito pirralhos desatentos e inquietos, de braços cruzados, olhar movediço e constante sorriso nos lábios (...) E fiquei supondo que aquele semi-homem, que tentava domesticar o gentio manso, como ele próprio considerava os seus buliçosos discípulos, era a encarnação rediviva do professor colonial, se ele tivera existido ou do 
moderno professor municipal, em plena radiação do atual século da criança, que vimos atravessando. (LIMA, 1921b, p.13).

Assim, a presença do higienismo no discurso educacional de Nestor dos Santos Lima, na década de 1920, descreve no seu recorte histórico um quadro sinótico de relações nas diferentes ordens do poder e do saber que caracterizam a materialidade dos seus pressupostos nos enunciados específicos de cada caso. As Modas e A Educação (LIMA, 1921a) e o Celibato Pedagógico (LIMA, 1927) são documentos desta materialidade do discurso educacional que se volta para a formação do professor a partir da perspectiva higienista de um agente formador da sociedade, guardião da ordem e prócer da civilização, tal como assinala esta passagem de Nestor Lima numa alocução aos formandos da Escola Normal de Natal em 1913:

Eu estou cada vez mais convencido de que a origem de todos os males é a ignorância: mas a ignorância das normas de educação na família, a carência das escolas, o pouco caso da sociedade, na obra que é a sua base o seu fundamento indispensável (...) E porque será essa a obra de todos os mestres digno do seu apostolado mas superiormente patriótico do que literário ou artístico é que prezados discípulos ao vir dar-vos a mão a acompanhar-vos na colação do grau eu invoco essa idéias da pátria através da bandeira e da missão a desempenhardes (...) unificando-as no vosso espírito para sempre apontar na trilha da vossa conduta. (LIMA, 1913b, p.24-25).

Com isto, a dimensão pedagógica no discurso educacional de Nestor Lima evidencia os pressupostos higienistas na condição característica da sua produção e da perspectiva de intervenção, a partir dos aspectos da configuração social da época, posta pelos saberes circulantes.

\section{O DISCURSO EDUCACIONAL E A NOÇÃO DE “EDUCAÇÃO COMPLETA”}

Considerado em seu aspecto geral o discurso pedagógico-educacional de Nestor Lima se apresenta no âmbito do lineamento histórico da educação brasileira. Primeiro, em torno daquilo que Carvalho (1998) identifica em Nagle (1976) como uma autonomização do campo educacional na passagem das décadas de 1910 e 1920. E depois, naquilo que de modo distinto Carvalho (1986) e Monarcha (1989) salientam como a lógica do antagonismo entre a tradição e o novo como "principal instrumento de progresso do país", enquanto uma crença comum das duas décadas, a qual transforma um "programa mais amplo de ação social num restrito programa de formação” (NAGLE, 1976, p.101, p.108).

Situando-se neste quadro histórico a construção do discurso pedagógico-educacional em Nestor Lima salienta o que pode ser entendido no âmbito da crítica de Carvalho (1998) como o caminho inverso da autonomização do campo educacional das esferas políticoeconômica e social. Ao contrário da autonomia a passagem da década de 1910 para a seguinte marca no conjunto dos seus enunciados uma progressiva explicitação das implicações do contexto sócio-político na concepção de educação escolar a partir dos desdobramentos inerentes à uma noção de educação completa que se delineia no Relatório da Escola Normal de 1912.

Tal noção aparece no nível de articulação da épistèmé, na organização dos enunciados do discurso, nos termos de uma nova pedagogia ou de uma pedagogia científica que se faz presente já nos seus artigos da coluna "Pedagogia" no jornal A República (1911) e posteriormente nos artigos da revista A Educação (1920 a, 1921 b). Ela revela uma amalgama 
de tipos de saberes pedagógicos, científicos e experimentais, de configurações e práticas de intervenções distintas, reunidas apenas pelo caráter normativo, seja no plano de fundamentação didático-pedagógica dos conteúdos curriculares, seja no plano da prática pedagógica ou da disciplina escolar.

Nessa medida, a postulação de uma nova pedagogia descreve uma perspectiva de inovação na dimensão discursiva, estruturadora da organização dos enunciados, a qual opera através de uma concorrência entre diversos saberes do campo pedagógico. Por exemplo, reúne saberes marcadamente científico-experimentais, como a "árvore pedagógica" de Pizzoli (1909) ou as medições biográficas de Quaglio (1911); ambos voltados para demarcação de padrões de normalidade; com aqueles de cunho mais psicossocial como a psicologia da criança de Claparède (1911) ou a "pedagogia da obediência" de Föerster (1910), ambos centrados no estudo do desenvolvimento infantil e da sua conformação em padrões sociais específicos.

A noção de "educação completa" de Nestor Lima aparece pela primeira vez no Relatório da Escola Normal, no item "Considerações Gerais, nas sugestões convenientes ao processo didático e a administração da escola" (RIO GRANDE DO NORTE, 1912, p.18) salientando a relevância da formação para o ensino. Sendo este último tomado sob a perspectiva articulada no início do relatório, em que a noção compreende a efetividade do contexto sócio-cultural na formação escolar.

Deste modo, uma concepção pedagógico-científica faz-se notar na inclusão da cadeira de Pedologia no plano de ensino, como um "estudo de anatomia e fisiologia" da criança, associado ao horizonte pragmático-metodológico da necessidade de "acompanhar esses estudos para perfeita adoção dos métodos de ensino e medidas comuns", sobrepondo-se a uma preocupação médico-higienista com a materialidade do processo de ensino, na solicitação de um "mobiliário higiênico e completo para o futuro prédio da escola" (RIO GRANDE DO NORTE, 1912, p.17-18).

Com isto, a perspectiva da educação completa se estabelece em torno do aparelhamento técnico, da adaptação e aperfeiçoamento instrumental, da salubridade física e intelectual do ambiente, e da ação pedagógica que tem por objeto a criança, a partir da elaboração de leis gerais e apreensão da vida infantil. Todos esses elementos articulados no quadro sócio-educacional conforme salienta Nestor Lima, acerca dos aspectos do reconhecimento e do apoio social:

Se não é notável o desenvolvimento que a Escola Normal tem tido em nosso seio. É - me lisonjeiro, entretanto assegurar que ela goza da confiança da sociedade e do governo, e disso tem recebido provas inequívocas. Ainda no fim do ano passado, quando o resultado das promoções e aprovações desagradou tão fundamental aos interessados, tive ocasião de verificar que não só o governo prestigiou com toda linha a Congregação, a parte insuspeita a sociedade aplaudiu-nos e entusiasmou-nos.

Necessário ainda se faz que os pais de família, liberando-se dos preconceitos sociais, tomam-vos-se a proficuidade da ação do magistério, com este cooperem no sentido de encorajar-se a instituição que nos tem dado e há de dar excelentes frutos (RIO GRANDE DO NORTE, 1912, p.11).

Nessa ordem, o conteúdo de uma educação completa traduz na sua composição as condições de entrelaçamento na forma discursiva de diferentes instancias do processo educativo, instaurando-se como um elo entre a perspectiva da formação do aluno - ou seja, da integralidade dos saberes na produção do conhecimento e observância total dos objetos nas práticas produtoras do ensino normal - e a perspectiva ampliada da função da formação 
escolar, estabelecida no corpo da sociedade pela dupla necessidade de inserção e reconhecimento social.

A compreensão de uma educação completa em Nestor Lima explicita a matriz de construção de todo um discurso pedagógico-educacional que também aparece no corpo dos relatórios da Escola Normal, a partir de uma proposta de modernização educacional na qual a própria concepção de Modernidade é articulada no nível dos saberes na época, achando-se indissociada da organização dos dispositivos pedagógicos, estabelecidos no nível das práticas, na configuração histórica das instituições sociais. De tal modo que, a perspectiva higienista de um modelo escolar permeia a compreensão de uma modernidade educacional, aparecendo de forma difusa em todos os itens do relatório, referindo-se não só à dimensão didáticopedagógica estrita - tipo de ensino e integração família-escola - mas, revelando-se em reiterados pedidos de compra de mobília escolar especial, ventiladores elétricos e material didático como laboratórios. Acrescendo-se também outras sugestões administrativas tais como: a "inspeção médica das escolas por parte da Inspetoria de Higiene ou de seus delegados a fim de verificar o estado higiênico do edifício e de fiscalizar os escolares do ponto de vista anatômico, fisiológico e patológico" (RIO GRANDE DO NORTE, 1914b, p.90).

Em síntese a noção central de "educação completa" traduz o seu significado em termos de um modelo ideal para o método pedagógico, cujo entendimento da sua integralidade revela-se como um critério essencial, estendido à totalidade dos vários aspectos educacionais, através de uma acepção ampla da formação, como proposta de um "ensino completo" (LIMA, 1921c, p. 2). Assim, a presença higienista na concepção pedagógicoeducacional de Nestor Lima encontra-se no núcleo estruturador da proposta do seu discurso enquanto um elemento necessário a compreensão da sua perspectiva de uma educação completa. Sendo que uma expressão mais acabada desta presença se materializará mais claramente, na década de 1920 num artigos acerca da moda e do vestuário das normalistas em 1921 e na tese defendida no I Congresso de Educação em 1927 sobre a importância do celibato das professoras.

\section{AS MODAS E O CELIBATO}

Os pressupostos característicos do pensamento higienista brasileiro da época (HERSCHMANN; KROPF; NUNES, 1996), se fazem presentes de modo especial em duas publicações de Nestor Lima que combinam os aspectos da identidade nacional, da moral e do gênero no exercício profissional da mulher tomados a partir do quadro dos valores e da demanda do papel social. A perspectiva de uma identidade nacional vinculada aos valores morais da sociedade aparece no artigo As Modas e a Educação (LIMA, 1921a) em torno da configuração do sujeito social caracterizado pelas normalistas. Do mesmo modo, a tese $\mathrm{O}$ Celibato Pedagógico (LIMA, 1927) vincula as condições do exercício profissional ao caráter de gênero em torno de um modelo idealizado da professora e do seu dever para com a sociedade.

O problema da identidade nacional, em torno do qual se associam argumentos sobre as condições climáticas e a autenticidade dos valores, evidencia no artigo As Modas e A Educação (LIMA, 1921a) a construção da identidade em conformação com a do sujeito social a partir da dimensão moral que esta assume na figura da normalista. A busca de um perfil brasileiro para o vestuário corresponde um modelo social idealizado que compreende um padrão de comportamento como a conduta socialmente aceita. Assevera o autor ao defender a adoção e a obrigatoriedade do uniforme escolar para as normalistas como um "traje específico (...) tão simples, modesto e confortável, quanto moral e higiênico”, argumentando ainda que 
"se coaduna com a natureza das funções, pela escola primária, dos novos espíritos verdadeiramente amantes do que a natureza lhes concedeu na terra, nos costumes, nas virtudes e nos hábitos característicos a nacionalidade" (LIMA, 1921a, p.19). Os argumentos de Nestor Lima articulam os pressupostos da Higiene e da Educação Física com o caráter moral da roupa apropriada, partindo do princípio que "toda vestimenta que não proteger suficientemente o corpo das irregularidades do meio atmosférico ou não o resguardar contra a curiosidade malsã dos olhares alheios não preenche o seu duplo fim higiênico e moral" (LIMA, 1921a, p.15). Adverte o autor logo no início do artigo:

O palpitante assunto das modas femininas está intimamente ligado à questão educativa. Primeiramente, porque é norma sediça de higiene, e, pois, de educação física, a necessidade de preservar o organismo das intempéries por meio do vestuário; em segundo lugar, porque um preceito da educação moral exige o resguardo ao pudor individual através do traje. (LIMA, 1921a, p. $15)$.

Assim, Nestor Lima ressalta do ponto de vista institucional "a preocupação de quem tem as responsabilidades de um estabelecimento de educação, freqüentado por $5 / 6$ de moças" e o concomitante "desejo de pô-las a salvo e ao abrigo de censuras" (LIMA, 1921a, p.15). E associa a sua defesa do uso do uniforme pelas normalistas o ponto de vista pedagógico, do vestuário adequado que obedece aos interesses primordiais da higiene e da moral, como também do exercício da função "quando a normalista faz às vezes de mestra e ensaia as suas propensões pedagógicas, num meio puramente escolar e apropriado" (LIMA, 1921a, p.19).

A normalização social da aparência, defendida pelo uso do traje apropriado, revela um dispositivo de controle da conduta correspondente aquele da identidade traduzida pela vestimenta que dá visibilidade aos padrões de comportamento. Para Nestor Lima não cabe apenas uniformizar o vestuário das normalistas, mas conformar-lhes o comportamento como um sujeito social, resguardando a ordem da constante ameaça dos valores, do gênero, do "grande mal, que lavra de norte a sul, onde os exageros da moda extravagante contaminam assustadoramente todo o sexo belo" (LIMA, 1921a, p.17, grifo do autor).

Contudo a ameaça que representa o desvirtuamento da moda não se restringe apenas aos valores da conduta social, mas antes aos elementos da identidade cultural e do patriotismo, que o autor observa sob a ótica da adequação da vestimenta aos valores nacionais. Conclama Nestor Lima a necessidade de um "traje nacional":

Quão sugestivo e grandioso seria, para os nossos estos de patriotismo, que se estabelecesse e cultivasse o traje brasileiro, definindo e caracterizando por toda parte a nossa estética e os traços do nosso patriotismo!? (...)Assim como hoje em dia cada nação, cada povo procura valorizar os seus produtos e elevar os seus caracteres específicos, em frente uns dos outros, devemos nós banir dos nossos costumes a macaqueação servil das modas ridículas, antihigiênicas e nem sempre morais, substituindo-as pelos trajes simples, confortáveis e belos, que realçam a beleza de quem os possuir, mas, não deflagram nem aumentam a magrém e a realdade de quem as tiver... (LIMA, 1921a, p.18, 19)

Para Nestor Lima, a identidade cultural se expressa nas especificidades do "traje nacional" como um vestuário que "conserva na simplicidade dos trajes locais e das suas cores características, toda essência das raças fortes de que descendem e que se perpetuam através de um dos seus belos aspectos: o bom gosto" (LIMA, 1921a, p.18). Assim, a postulação de uma vestimenta higiênica associa os aspectos do progresso e da tradição cultural, possibilitando 
aos olhos do autor, um ponto de vista conservador senão de preservação da tradição e adaptação ao progresso como também do processo civilizatório. Tal como revela o teor da sua crítica:

É, porém, de lamentarmos profundamente que esse vai-e-vem da moda não a encaminhe para o estabelecimento da nossa moda única, de uma vestimenta caracteristicamente nacional, em que se retratem os nossos hábitos ancestrais, combinados com as vantagens da higiene e as exigências do decoro de cada sexo. (LIMA, 1921, p.18).

De outro modo, os pressupostos higienistas da condição biológica e do gênero que estão na base da compreensão do artigo de 1921, As modas e A Educação, reaparecem no discurso educacional de Nestor Lima em 1927 com a tese do Celibato Pedagógico associandoos a capacidade da mulher e o exercício da função. Seu objeto agora não é mais a normalização no nível da conformação social das normalistas, mas sim da naturalização dos valores no nível técnico da competência profissional. A tese põe em questão o papel da mulher a partir do princípio da família como célula-mater da sociedade e a hierarquia de valores decorrentes deste contexto.

A tese O Celibato Pedagógico (LIMA, 1927), defendida na I Conferência Nacional de Educação caracteriza na esfera do discurso um documento específico relativo ao contexto histórico do movimento nacional pela educação. Nestor Lima compôs na ocasião a mesa diretora dos trabalhos da I Conferência ao lado de nomes como o de Lourenço Filho. Ele alinhou o seu trabalho no mesmo campo das teses com caráter higienista como aquelas sobre "O problema da Educação Sexual" de Renato Kehl e a "Educação Sexual" de Luis Antonio Lima, ou ainda outras, com caráter propedêutico e profilático a exemplo de "Como se pode fazer a Assistência Médica aos Alunos Pobres das Escolas Primárias" de Leonel Gonzaga e "Por que se impõe a primazia da Educação Higiênica Escolar" de Belizário Penna (FERREIRA, 1993, p.4, p.52, p.48).

A tese defendida por Nestor Lima destaca a ótica da conformação de um modelo educacional colocado sob as perspectivas da formação profissional e da naturalização de um perfil social, a partir de uma matriz de fundamentação fisiológica-eugenista, estruturada em termos factuais da legislação e do exercício feminino do magistério. A tese consubstancia seu principal argumento nas ordens da avaliação técnica do Departamento de Educação e da experiência das Leis Estaduais nº 405 de 1916 e nº 677 de 1927 (RIO GRANDE DO NORTE, 1930) que concedem respectivamente "licença de dois meses às professoras grávidas" e "o instituto da licença especial", prerrogativas legais que para Nestor Lima "vem resultando francamente desfavorável ao ensino público, sempre a voltas com as ausências das suas regentes" (LIMA, 1927, p.5). Assim, o autor argumenta na apresentação da sua tese:

É muito mais grave e séria do que parece a questão do celibato feminino ou da condição de mulher casada, em face da educação e do ensino como profissão habitual (...) No Brasil, as soluções dadas pelos Regulamentos oficiais não resultam do estudo acurado das opiniões bem avisadas, mas se vão fazendo ao léo do sentimentalismo ou da aversão dos redatores ou inspirados dos decretos governamentais. A lei da reforma primária de Minas Gerais só dá acesso ao magistério a professoras solteiras, ou viúvas sem filhos (...) A ser verdadeira a informação, está declarada a guerra ao matrimônio das educadoras oficiais, enquanto que aos profissionais ou outro sexo ninguém se lembrou sequer de pôr-lhes restrições, quanto mais de proibir-lhes as justas núpcias. Mas, também, se razões de sobra existem para 
aquela proibição, ao contrário, nenhuma se invoca em favor desta última. (LIMA, 1927, p.3).

A proposta do celibato se pauta no princípio de uma hierarquia de valores estabelecida em torno do papel da mulher na sociedade, a partir do princípio da família como célula-mater da sociedade. Deste modo, ser mãe e professora constituiria um perigo a boa educação e um caráter nocivo ao funcionamento do organismo social. Sendo que, uma vez codificado o exercício profissional na forma da lei, Nestor Lima levanta contra esse duplo caráter um antagonismo inerente entre a concepção idealizada do gênero e a sua facticidade. Argumenta o autor:

O ideal da educação pública seria fazer desta o prolongamento dos lares; e quem melhor que as mães, poderia educar a infância alheia por virtude dos seus predicados naturais já postos em prova na família e pelo exercício do magistério, que lhes dá o necessário traquejo e perícia educativa? Mas é que esse beneficente idealismo opõe-se realidades muito fortes e desconcertantes (...) O que a prática nos ensina, diária e diuturnamente, é que o exercício simultâneo das duas funções - doméstica e pedagógica - se não são absolutamente incompatíveis, são, ao menos, prejudiciais à perfeição, à regularidade e à proficuidade de cada um deles. (LIMA, 1927, p.4, p.6).

Assim, é em torno da discussão jurídica se: "teremos dado um passo avante ou teremos contribuído diretamente para prejuízos certos e indeclináveis do ensino oficial?”, que o argumento inicial do autor se desdobra numa preocupação humana expressa no juízo de que "o legislador potiguar não viu mal, é certo, o problema da proteção ao ventre e colocou-se no ponto de vista humano e sentimental, embora, com sacrifício talvez do público interesse" (LIMA, 1927, p.6). Nessa medida, Nestor Lima articula em torno dos enunciados jurídicos uma perspectiva humanista que possibilita a defesa do celibato para as professoras na legislação, a partir do pressuposto higienista do modelo biológico do gênero aplicado às exigências da função. A naturalização social se consubstancia através dos enunciados da fisiologia que se coloca sob a ótica científica do autor na fundamentação da sua defesa do celibato. Nestor Lima procura demonstrar a partir da perspectiva eugenista, da higiene mental, o aspecto do desgaste físico da mulher e denota até uma preocupação humanitária com a sua condição, tal como se verifica nesta passagem:

Por mais diligente e laboriosa que a mulher seja, não poderá dar conta dos encargos da família, cuidar dos filhos e do marido, dirigir os empregados, enfim, a própria habitação, providenciando a tempo e a hora acerca de tudo quanto é necessário a regularidade da vida doméstica, de que é ela o fulcro e o ponto central, e por outro lado, preparar bem as lições, dispor metódica e previamente o seu trabalho, fazer a escrituração da classe, estudar e ilustrarse constantemente, comparecer a hora marcada, esgotar o horário, preocupada tão somente com o seu mister pedagógico, sem os sobressaltos e o temor dos chamados urgentes e dos reclames aflitos de casa (...) O trabalho mental da professora esgota e destrói os nervos, assim ela não pode contribuir para formar uma progênie sadia. Os eugenistas afirmam que as mulheres quer trabalham mentalmente são pouco aptas para a profissão maternal." (LIMA, 1927, p.4).

Em síntese, tanto em "As Modas e A Educação", de 1921, quanto na tese sobre "O Celibato Pedagógico", de 1927, essa descontinuidade entre as publicações e a articulação geral dos pressupostos higienistas no discurso educacional de Nestor Lima denotam uma 
construção pedagógico-educacional, relativa à delimitação do conteúdo descrito, como uma formação discursiva superposta as dimensões da produção do saber e das práticas na caracterização dos diferentes enunciados. A dimensão da produção do saber corresponde a épistèmé aplicada à prática na esfera da formação do discurso; ao passo que, as práticas de saber correspondem à dimensão prática produtora do discurso, enquanto práticas constitutivas de saberes que se alinham dentro do quadro histórico. Deste modo, uma unidade discursiva se articula entre estas dimensões sobrepostas, modeladas pela noção de "educação completa" em Nestor Lima (MENEZES, 2003), localizada no campo das técnicas e dispositivos pedagógicos de análise e adequação das particularidades ao quadro geral da formação.

\section{CONSIDERAÇÕES FINAIS}

Situada na órbita dos conteúdos de época relacionados às publicações sobre as modas e o celibato, a articulação da temática educacional com o pensamento higienista se estabelece em torno da compreensão de uma educação completa por Nestor Lima, a partir de uma perspectiva tomada da pedagogia clássica. Esta última traça no conjunto das suas finalidades um esboço da visão normalizadora, que se faz presente nas publicações, a partir de uma concepção ou de um método pedagógico que associa o critério específico as modernas perspectivas de progresso e regeneração moral com o modelo tradicional de formação do indivíduo no âmbito da instrução propriamente dita. Com isto, a perspectiva integral da educação, compreendendo todo o contexto e o processo educativo, articula as esferas da racionalidade pedagógica e da produção social sob a ótica de um mesmo horizonte de um quadro de saberes e práticas centradas no indivíduo e na sua função social.

$\mathrm{O}$ artigo sobre as modas e a tese sobre o celibato compõem, no conjunto dos seus enunciados, um horizonte normalizador que não se faz presente no ensino nem nas práticas pedagógicas, mas que se materializa em torno do aspecto da formação do professor, especificamente, no dispositivo que se encontra relacionado à sua formação e desempenho, concernente às dimensões física, intelectual e moral deste, vinculadas a boa conduta e ao bom exercício profissional. Os temas da moda e do celibato circunscrevem então o campo de relações da perspectiva da educação completa com os pressupostos ético-higienistas, parâmetros de balizamento da normalização social, problematizados em torno daquilo que tange a conformação técnica e social da figura da professora, sua atitude e as exigências do exercício do magistério.

Forma ampliada da organização dos saberes no discurso educacional da época, o higienismo constitui nessa medida o campo educacional de um dispositivo de saber que incorpora dito, não dito e lógica social, a partir da perspectiva de uma formação integral de caráter normalizador. A educação completa articula no domínio da formação integral o total conhecimento do sujeito como objeto educativo, centrando-se simultaneamente nos campos dos saberes e das práticas, atuando em camadas distintas do conjunto das dimensões física, intelectual e moral da formação do indivíduo. Noutros termos, ela opera através dos pressupostos do saber e das práticas higienistas, um dispositivo de produção constante de tecnologias de adequação do sujeito às esferas normativas e fisiológicas, enquanto formas de ortopedização sócio-educacionais dos corpos e dos indivíduos estabelecidas no âmbito da ordem social.

As figuras da normalista e da professora que aparecem delineadas nas publicações com protagonistas dos debates sobre as modas e o celibato correspondem aquela do quadro da produção histórica do dispositivo normalizador, da consolidação da ordem republicana, de um mecanismo social a quem cabe a formação do cidadão e a construção da identidade nacional. 
Assim, a perspectiva de uma educação completa caudatária do higienismo como a ideologia cientifica vigente, evidencia a matriz de um modelo educacional de interpretação e intervenção social, no âmbito dos pressupostos aplicados as práticas pedagógicas e educativas, que tem por objeto tanto a formação das professoras quanto as condições do seu ofício, naquilo que concerne até mesmo ao estatuto fisiológico e ao do modo de gestão da vida.

Por fim, a presença de um objeto comum no pressuposto higienista da proposição de quem deve cuidar e como deve ser cuidado, prefigura dentro da engrenagem social a importância das propostas assinaladas em torno das modas e do celibato, na medida em que juntas, reunidas em torno da figura do educador, expõem uma ambivalência do dispositivo de normalização. De um lado, a homogeneização social e a moldagem moral da normalista no estágio de formação da identidade e inserção numa cultura institucional. E, de outro, a exigência de um modelo de gestão da vida do professor para o pleno exercício do magistério. Uma vez que se torna vital para a própria dinâmica da produção social formar o virtual formador e, no nível mais elementar, gerir a vida daquele que também se configura como gestor.

\section{Referências}

BARATA, Rita Barradas. Epidemiologia e saber científico. In: Revista Brasileira de Epidemiologia, v. 1, n. 1, 1998, p. 14-27.

CANGUILHEM, Georges. Ideologia e Racionalidade nas Ciências da Vida. Lisboa: Edições 70, 1983.

CARVAlHO, Marta Maria Chagas de. Molde Nacional e Forma Cívica: Higiene, Moral, Trabalho no Projeto da Associação Brasileira de Educação. Bragança Paulista: EDUSF, 1998.

. Molde Nacional e Forma Cívica: Higiene, Moral, Trabalho no Projeto da Associação Brasileira de Educação (1924-1931). 1986. Tese (Doutorado em Educação) Faculdade de Educação, Universidade de São Paulo. São Paulo, 1986. (Apresentação, p.1-27).

CASCUDO, Luis da Câmara. História do Rio Grande do Norte. Rio de Janeiro: Departamento de Imprensa Nacional, 1955.

O Livro das Velhas Figuras, v.VIII, pesquisas e lembranças na História do Rio Grande do Norte.Natal: EDUFRN, 2002.

CLAPARÈDE, Edouard. Psychologie de l'Enfant et Pédagogie expérimentale. Genève: Libraire Kündig, 1911.

COMPAYRÉ, Gabriel Cours de Pédagogie. Théorique et Pratique. Paris: Paul Delaplane, 1906.

Paul Delaplane, 1908.

Psychologie Appliqué à Éducation. Deuxieme Portie. Application. Paris: 
DANTAS, Cristovam. A criança e a eugenia. In: Revista do Centro Polimático do Rio Grande do Norte. Natal, agosto, 1920, p.3-8.

DUFESTEL, L. Hygiène Scolaire. Paris: Octave Doin et Fils, 1909.

FERREIRA, Suzana da Costa. A I Conferencia Nacional de Educação. Contribuição para o estudo das origens da Escola Nova no Brasil. Brasília: INEP, 1993.

FOERSTER, F. L'École et le caractère. Le pédagogie de l'obéissance et la réforme de la discipline scolaire. Trad. Pierre Bovet. Saint-Blaise: Foyer Solidariste, 1910.

FOUCAULT, Michel. Les mots et les choses. Une archeologie des sciences humaines. Paris: Gallimard, 1966.

L’archéologie du savoir. Paris: Gallimard, 1969.

Surveillir et punir. Paris: Gallimard, 1975.

.Histoire de la sexualité I. La volonté de savoir. Paris: Gallimard, 1976.

Dits et écrtis, 1954-1988. v. III, 1976-1979. Paris: Gallimard, 1984.

HERSCHMANN, Micael; KROFP, Simone P.; NUNES, Clarice. Missionários do Progresso. Médicos, Engenheiros e Educadores no Rio de Janeiro, 1870-1937. Rio de Janeiro: Diadorim, 1996.

LE BON, Gustave. Psychologie de l'Éducation. Paris: Ernest Flamnarion, 1909.

LASSABLIÈRE, P. Hygiène Infantile. Paris: Jauve et Cie, 1911.

LIMA, Nestor dos Santos. Instrução Moral e Cívica e Economia Doméstica. Métodos e Processos. A República. Coluna Pedagogia, Natal, 23 ago. 1911, p.1-2.

Typgraphia do Instituto, 1913a.

Melhoramentos Técnicos do Ensino Primário e Normal. Natal:

O Culto da Pátria e a Missão dos Mestres. Natal: Empreza typographica Natalense, 1913b.

As Modas e a Educação. Pedagogium, Natal, v. 1, n. 2, nov.1921a, p. 15-20.

Natalense, $1921 b$.

Síntese do Nosso Movimento Pedagógico. Natal: Empreza typographica

Métodos Gerais de Ensino, seu valor, regras, requisitos e divisões. A Educação, Órgão do Grêmio Normalista. Natal, v. 4, n. 1, maio 1921c, p. 2-4.

Da Organização do Ensino Normal, Profissional e Primário no Sul do

Brasil e no Rio da Prata. Natal: Typographia d" "A República", 1923. 
Pinto \& L, 1927.

O Celibato Pedagógico Feminino. Natal: Typographia Commercial - J.

MENEZES, Antonio B. N. T. de. Nestor dos Santos Lima e a Modernidade Educacional: uma história do discurso (1911-1928). 2003. Tese (Doutoramento em Educação) Programa de Pós-Graduação em Educação da Universidade Federal do Rio Grande do Norte. UFRN, Natal, 2003.

MONARCHA, Carlos. A reinvenção da cidade e da multidão. Dimensões da modernidade brasileira: a Escola Nova. São Paulo: Cortez/Autores Associados,1989.

MONTESSORI, Maria. Manual Prático del Método Montessori. Barcelona: Araluce, 1915.

NAGLE, Jorge. Educação e Sociedade na Primeira República. São Paulo: EPU; Rio de Janeiro: Fundação Nacional do Material Escolar, 1976.

PAULHAN, Fr. Les Caractères. Paris: Felix Alcan, 1909.

PEIXOTO, Julio Afrânio. Elementos de Medicina Legal. Rio de Janeiro: Francisco Alves, 1914.

PETROVICH, Enélio Lima. Nestor dos Santos Lima - aspectos de sua vida e obra. Revista do Instituto Histórico-Geográfico do Rio Grande do Norte, Natal, v. 79-80, 1987 e 1988.

PIZZOLI, Uggo. Pedagogia Scientifica. Mileno: Francesco Vallardi, 1910.

QUAGLIO, Clemente. Compêndio de Pedologia. Guia do professor para execução da folha biográfica nas escolas primárias. São Paulo: Typ. Siqueira, 1911.

RIO GRANDE DO NORTE. Relatório do Diretor da Escola Normal, apresentado ao Dr. Manoel Dantas, Diretor-Geral da Instrução Pública. Natal, set. 1912.

Governo do Rio Grande do Norte. Leis e Decretos (1908-1913). Natal: Typografia A República, 1913.

.Relatório do Diretor da Escola Normal, apresentado ao Dr. Manoel Dantas, Diretor-Geral da Instrução Pública. Natal, set. 1914.

A Reforma do Ensino. Texto e comentário da Lei 405 de 29 de Novembro de 1916. Natal: Typographia A República, 1917.

. Governo do Estado do Rio Grande do Norte. Leis e Decretos (1920-1930). Natal: Typographia A República, 1930.

Recebido em abril/2012

Aprovado em agosto/2012 